\title{
Age profiles of sport participants
}

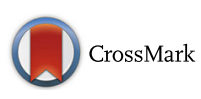

\author{
Rochelle M. Eime ${ }^{1,2^{*}}$, Jack T. Harvey ${ }^{1,2}$, Melanie J. Charity ${ }^{1,2}$, Meghan M. Casey ${ }^{2}$, Hans Westerbeek ${ }^{1}$ \\ and Warren R. Payne ${ }^{1}$
}

\begin{abstract}
Background: Participation in sport has many health benefits, and is popular amongst children. However participation decreases with age. While the membership records of peak sports organisations have improved markedly in recent years, there has been little research into sport participation trends across the lifespan. This study investigates age profiles of participation in sport and compares these trends between genders and residential locations.

Methods: De-identified 2011 participant registration data for seven popular Australian sports (Australian Football, Basketball, Cricket, Hockey, Lawn Bowls, Netball and Tennis) were obtained and analysed according to age, gender and geographical location (metropolitan $\vee$ non-metropolitan) within the state of Victoria, Australia. All data were integrated and sports were analysed collectively to produce broadly based participation profiles while maintaining confidentiality of membership data for individual sports.

Results: The total number of registered participants included in the data set for 2011 was 520,102. Most participants (64.1\%) were aged less than 20 years. Nearly one third (27.6\%) of all participants were aged 10-14 years, followed by the 5-9 year age group (19.9\%). Participation declined rapidly during adolescence. A higher proportion of males than female participants were young children (4-7 years) or young adults 18-29 years; this pattern was reversed among 8-17 year-olds. A higher proportion of metropolitan participants were engaged between the ages of 4-13 and 19-29, whereas a higher proportion of non-metropolitan participants played during adolescence (14-18 years) and throughout mature adulthood (30+ years).

Conclusions: Increasing participation in sport is an objective for both government and sporting organisations. In order to have both mass population-based participation, from a health policy and elite performance perspective, we need to further explore the findings arising from the analysis of this extensive data set. Such an examination will lead to better understand of the reasons for attrition during adolescence to inform program and policy developments to retain people participating in sport, for a healthy and sport performing nation.
\end{abstract}

Keywords: Sport, Participation, Age patterns

\section{Background}

Sport is a common form of Leisure Time Physical Activity (LTPA) [1, 2] which has been shown to result in many health benefits. Recent systematic reviews found that there are many psychological and social health benefits specifically associated with participation in sport for children, adolescents and adults [3, 4]. There is consistent evidence that those who participate in club-based and/or team-based sport participation can have better psychological and social health outcomes than those that

\footnotetext{
* Correspondence: rochelle.eime@vu.edu.au

${ }^{1}$ Institute of Sport, Exercise and Active Living, Victoria University, PO Box 14428, Melbourne, Victoria 8001, Australia

${ }^{2}$ School of Health Sciences and Psychology, Federation University, Ballarat, Australia
}

only engage in individual types of physical activity (PA) $[3,4]$. The social nature of club- and team-based sport is suggested to mediate these health outcomes, although the psychological and social health benefits of sport participation differ between children, adolescents and adults. For children and adolescents social health benefits are more prominent, such as development of social skills through opportunities for social interaction and improved self-esteem, whereas sport participation among adults is more likely to lead to better psychological health, including reduced stress and distress $[3,4]$. In addition to the mental and social health benefits, club sport has been shown to be associated with greater physical health benefits at low 
and moderate levels of participation, than participation in individual-based physical activities such as walking [5]. From a public health perspective, sport during adolescence is a strong predictor of PA later in life $[6,7]$.

Understanding participation patterns in sport is also important for a range of key stakeholders including government, sport and recreation, and health organisations, and in particular sport governing bodies [2]. Populationlevel sport participation patterns can inform evidencebased strategic and policy planning and development $[8,9]$ and facilitate the achievement of desirable outcomes. For instance, in Australia the National Sport Policy Framework provides a guide outlining the importance of sport policies and coordinated strategies at both the community and elite levels for increased participation and a healthy nation, as well as for international success of elite athletes [10].

Sport participation patterns are typically explored according to age and gender. There is evidence that sport participation is a young persons' activity [11], with reports that participation levels peak at ages 12-13 years [12]. However, others have found that for Belgian boys aged 13-18 years, there was a linear increase in sport participation until age 16.8 years, before participation declined [13]. Another study of sport and PA participation by girls found that overall PA levels did not significantly change throughout adolescence, but that the context of participation changed [14]. Older adolescent females (16-18 years) shifted their participation away from organised, competitive modes and settings towards non-organised and non-competitive modes and settings and were more likely to then participate in individual types of PA [14].

For adults, the relationship between sport participation, age and gender has been found to differ amongst European countries [15]. In France, Latvia, Slovakia and the UK, males reported significantly more sport participation than women in the young adult age group (18-34 years). In Belgium and Greece, males were more likely to participate than females in both the young adult (18-34 years) and older adult (55 years and older) categories [15]. In contrast, Swedish women were more active than males in the young adult category (18-34 years); whilst in Finland this was only true for the middle-age group (35-54 years) and in Denmark for the older adults (55 years and older) [15]. In Australia, sport participation in an organised context was dominated by those aged 15-34 years compared to all older age groups, for both males and females [2]. Similarly in Spain, the prevalence of participation in sport decreased as age increased [16]. Amongst older adults aged 58-67, sport participation has also been found to decrease with age [17].
There are significant gender differences in sports participation in European countries, where males were more likely to participate in sport more regularly than females in Belgium, France, Greece, Latvia, Lithuania, Slovakia, Spain and the UK, whilst the opposite was true for Denmark, Finland, Sweden and the Netherlands [15]. The authors point out that historically male participation in sport has dominated over female participation, however some policy developments targeted at increasing participation in sport for females may have contributed to higher participation rates for females in some countries [15]. For instance in Belgium, available data show a greater level of male than female participation, females have closed the gap considerably since the 1970s [18]. However, with regard to the club based, organised context of sport participation, there were no gender differences detected in the Belgian study [18]. Amongst older Dutch adults, males and females were equally likely to participate in sport, or to be a sports club member, however participation in competition was more likely to occur amongst males rather than females [17].

In general, the above research provides evidence that as age increases participation in sport decreases. However, these studies are often limited to self-report sample surveys and/or to specific age ranges. Furthermore, most studies do not compare different residential locations. It is important to better understand participation in sport and how it relates to age, gender and geographical location, in order to inform evidence-based, well targeted program and policy development. The aim of this study was to use a unique, very large set of comprehensive membership registration data, effectively a census of participation, to provide age profiles of participation across seven major sports $[14,19]$, across the lifespan, and to compare these trends between genders and residential locations.

\section{Methods}

We investigated profiles of sport participation according to age, gender and geographical region in the Australian state of Victoria. As part of the Sport and Recreation Spatial project (www.sportandrecreationspatial.com.au) the authors of this study have initiated a large repository of sport registration data to inform evidence-based decision making across the sport sector. The seven sports incorporated in the study (Australian Football, Basketball, Cricket, Hockey, Lawn Bowls, Netball and Tennis) include six of the 10 most popular adult club-based physical activities in Australia, and five of the 10 most popular organised physical activities for children [20]. De-identified data on participant registrations were obtained from the respective state sporting associations (SSAs), the sports' state governing bodies. In this way 
the study was able to overcome the limitations of many studies in this area, such as the use of self-reported data, narrowly defined player population segments and failure to examine geographical variation.

Of the seven SSAs engaged in the study, five register participants for a calendar year with age determined at 1 January, and two register participants for a financial year, with age being calculated as at 1 July. The scope of this study was nominally the calendar year 2011; we included 2011 registrations for five sports and 2011-12 registrations for two sports. Ethics approval was granted by the Federation University Australia Human Research Ethics Committee.

All data were integrated and sports were analysed collectively in order to produce broadly based participation profiles while maintaining confidentiality of membership data for individual sports. An individual could engage in more than one sport and was counted separately in each sport, with the result that counts of participants are to some extent weighted by individuals' levels of participation. Because of anonymity provisions, it was not possible to identify participation of a particular individual in more than one sport, but based on an analysis of demographic characteristics and residential postcodes, the proportion of individuals who were registered in more than one sport was estimated to be around $12 \%$ across Victoria. The methods of data integration and analysis have been reported previously [21].

Regional breakdowns were based on residential postcodes. Although postcode areas are not precisely geographically specified, the Australian Bureau of Statistics (ABS) precisely defines approximations to postcode areas entitled postal areas [22]. ABS also produces a correspondence table for assigning population-weighted proportions of postal areas to local government areas (LGAs) [23], which enabled estimated numbers of participant registrations in each LGA to be calculated. The 79 Victorian LGAs are classified as metropolitan (31 LGAs) or non-metropolitan (48 LGAs) by the Victorian state government [24].

It is important to emphasise that the age profiles reported throughout this paper are based on proportions of all participants, not on age-specific participation rates. The outcome variable, the proportion of participants in an age category, was defined as the number of registered members in that age category, expressed as a percentage of the total number of participants of all ages. This resulted in standardised profiles that could be directly compared between genders and regions. The alternative approach of expressing each number of participants as a proportion of the population in the same age category (i.e. a participation rate) would result in profiles with different scales due to different overall participation rates for the different genders and regions. Furthermore, ABS inter-censal population estimates are only published for 5 -year age cohorts, whereas there is no such limitation for participant age profiles because the birthdate, and hence the exact age, of each participant is known.

Two sets of age profiles were tabulated and graphed. The first covers the whole life span, tabulated in 5-year age ranges and graphed in single-year age ranges, and the second provides a more detailed single-year picture of the 4-29 year age range. In each case, overall age profiles and separate profiles for each gender and region are presented.

Because data were collected from the whole population of members of each sport, i.e. a census rather than a sample, statistical inference was not applicable. Analyses were conducted using Excel and SPSS Version 21.

\section{Results}

The seven sports have been de-identified in all results presented. While a small proportion of participants registered in Victoria resided in other states, only those residing in Victoria were included. After consultation with SSAs, the valid age range was considered to be 4-100 years. Those for whom no birthdate were recorded $(n=34,341 ; 6.2 \%)$ were excluded from the analysis, as were those whose calculated ages at the appropriate registration date were outside the valid age range $(n=974 ; 0.2 \%)$. The remaining number of registered participants in the seven sports ranged from 13,275 to 171,304 , with the total number of registered participants for 2011 being 520,102.

\section{Overall trends}

Table 1 provides age profiles of registered sport participants, and breakdowns by gender and region, within standard ABS 5-year age cohorts (plus a separate 4-yearold cohort). Most participants (64\%) were aged less than 20 years. Nearly one third of all participants were aged between $10-14$ years $(27.6 \%)$, followed by the $5-9$ year age group (19.9\%) and the 15-19 year age group $(15.3 \%)$. Fewer than $10 \%$ of participants were over the age of 50 years. Given that the great majority of participants $(79.1 \%)$ in the seven sports were aged from 4-29 years more detailed age profiles are presented in Table 2.

\section{Gender}

Tables 1 and 2 and Figs. 1 and 2 show that, in terms of sport participation by gender, a higher proportion of male participants were very young (4-7 years) (13.8\%) compared to females $(7.3 \%)$; this pattern was repeated in young adulthood (18-29 years; $20.4 \%$ and $17.5 \%$ for males and females, respectively). A higher proportion of female participants were aged 8-17 (53.9\%) than males $(45.0 \%)$. The proportion of female participants aged 
Table 1 Age profiles of registered sport participants: percentage of total sport participants

\begin{tabular}{lccccc}
\hline Age (years) & Participants (\%) & Male (\%) & Female (\%) & Metropolitan (\%) & Non-Metropolitan (\%) \\
\hline 4 & 1.3 & 0.5 & 1.7 & 1.5 & 0.9 \\
$5-9$ & 19.9 & 17.1 & 21.5 & 21.5 & 17.0 \\
$10-14$ & 27.6 & 32.1 & 25.6 & 28.1 & 26.7 \\
$15-19$ & 15.3 & 7.8 & 15.1 & 14.7 & 16.5 \\
$20-24$ & 8.8 & 5.4 & 9.1 & 6.0 & 8.5 \\
$25-29$ & 6.1 & 3.8 & 6.3 & 4.3 & 5.8 \\
$30-34$ & 4.1 & 3.5 & 4.2 & 2.9 & 4.2 \\
$35-39$ & 3.0 & 6.0 & 2.8 & 4.9 & 3.4 \\
$40-49$ & 5.0 & 2.5 & 2.6 & 2.3 & 5.2 \\
$50-59$ & 2.5 & 2.6 & 2.6 & 3.0 \\
$60-69$ & 2.6 & 3.0 & 3.9 & 2.8 & 3.8 \\
$70+$ & 3.6 & 2.6 & & 5.1 \\
\hline
\end{tabular}

Table 2 Age profiles of registered sport participants aged 4-29 years: percentage of total sport participants

\begin{tabular}{|c|c|c|c|c|c|}
\hline Age (years) & Participants (\%) & Male (\%) & Female (\%) & Metropolitan (\%) & Non-Metropolitan (\%) \\
\hline 4 & 1.3 & 1.7 & 0.5 & 1.5 & 0.9 \\
\hline 5 & 3.0 & 3.8 & 1.4 & 3.3 & 2.5 \\
\hline 6 & 3.5 & 4.1 & 2.2 & 3.8 & 2.8 \\
\hline 7 & 3.8 & 4.2 & 3.2 & 4.2 & 3.2 \\
\hline 8 & 4.5 & 4.5 & 4.6 & 4.8 & 4.0 \\
\hline 9 & 5.0 & 4.8 & 5.6 & 5.3 & 4.5 \\
\hline 10 & 5.9 & 5.4 & 6.9 & 6.2 & 5.4 \\
\hline 11 & 5.9 & 5.4 & 6.9 & 6.1 & 5.5 \\
\hline 12 & 5.7 & 5.3 & 6.4 & 5.7 & 5.6 \\
\hline 13 & 5.3 & 4.9 & 6.2 & 5.3 & 5.3 \\
\hline 14 & 4.9 & 4.6 & 5.6 & 4.8 & 5.0 \\
\hline 15 & 4.2 & 3.9 & 4.8 & 4.0 & 4.5 \\
\hline 16 & 3.6 & 3.4 & 4.0 & 3.3 & 4.0 \\
\hline 17 & 2.8 & 2.8 & 2.9 & 2.6 & 3.2 \\
\hline 18 & 2.5 & 2.6 & 2.2 & 2.4 & 2.5 \\
\hline 19 & 2.3 & 2.4 & 2.0 & 2.3 & 2.2 \\
\hline 20 & 2.1 & 2.1 & 1.9 & 2.1 & 2.0 \\
\hline 21 & 1.9 & 2.0 & 1.7 & 1.9 & 1.9 \\
\hline 22 & 1.7 & 1.8 & 1.5 & 1.8 & 1.7 \\
\hline 23 & 1.6 & 1.7 & 1.4 & 1.7 & 1.5 \\
\hline 24 & 1.5 & 1.5 & 1.3 & 1.5 & 1.4 \\
\hline 25 & 1.4 & 1.5 & 1.3 & 1.5 & 1.3 \\
\hline 26 & 1.3 & 1.3 & 1.2 & 1.3 & 1.2 \\
\hline 27 & 1.2 & 1.2 & 1.1 & 1.2 & 1.1 \\
\hline 28 & 1.1 & 1.2 & 1.0 & 1.2 & 1.1 \\
\hline 29 & 1.0 & 1.1 & 0.9 & 1.1 & 1.0 \\
\hline Total \% in 4-29 year age range & 79.1 & 79.3 & 78.6 & 81.2 & 75.4 \\
\hline
\end{tabular}




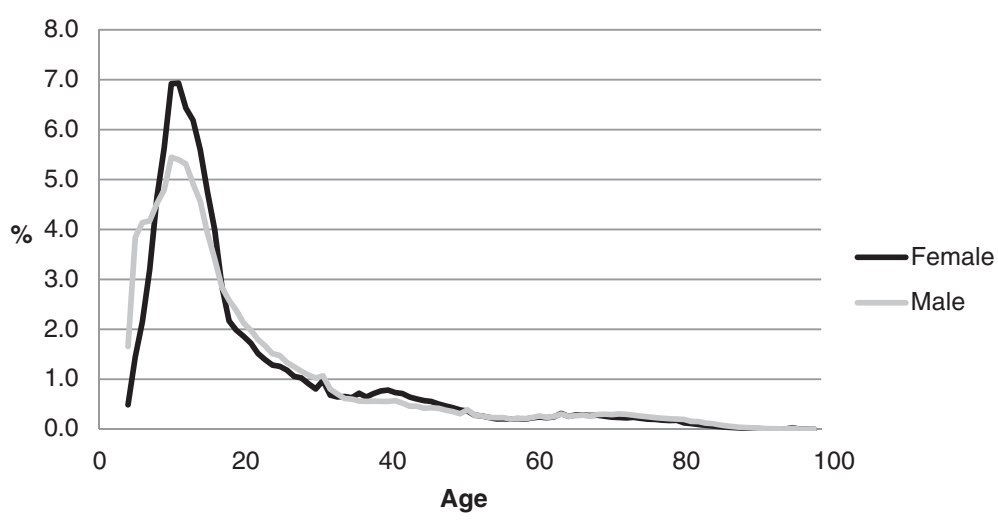

Fig. 1 Age profiles by gender

30-49 was again slightly higher compared to males. Beyond age 50, gender differences were negligible.

A deeper examination of the data revealed that the highest proportion of participants for both males and females was in the 10-11 age group (5.4\% and $6.9 \%$ for males and females, respectively). For all age groups with a proportion of participants of $4 \%$ or more, the males were younger (aged 6-14) than the females (aged 8-16). This represented a 9-year span for both genders. A much higher proportion of male participants were aged 4-5 (5.5\%) than was the case for females (1.9\%).

\section{Region}

Tables 1 and 2 and Figs. 3 and 4 provide details of the age profiles by geographical region. Higher proportions of metropolitan than non-metropolitan registered sport participants were engaged in the seven sports between the ages of 4-12 and ages 19-29; whereas higher proportions of non-metropolitan registered participants were engaged during adolescence ( $14-18$ years $)$ and throughout most of adulthood (30+ years).

A closer analysis of the 4-29 year age group, where around $80 \%$ of the participation occurs, showed some key differences in age between metropolitan and nonmetropolitan registered sport participants. The ages of 4-12 years represented a higher proportion of all metropolitan registered sport participants than for nonmetropolitan. This difference was reversed from ages 14-18 years onward.

\section{Discussion}

This study is unique in providing population-derived age profiles of club sport participation within popular organised sports in Australia. A strength of this study is in the number of total participants $(n=520,102$ member records), representing the whole population of registered participants for seven popular sports in the state of Victoria, Australia in 2011. However, it must be noted

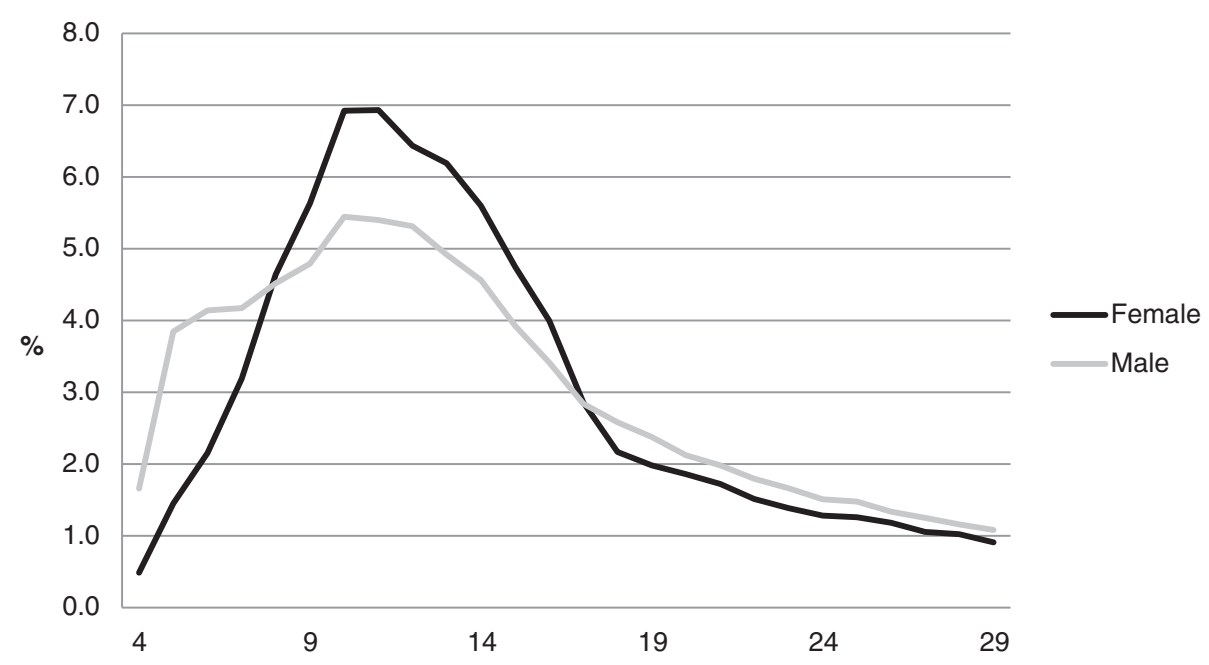

Fig. 2 Age profiles (4-29 years) by gender 


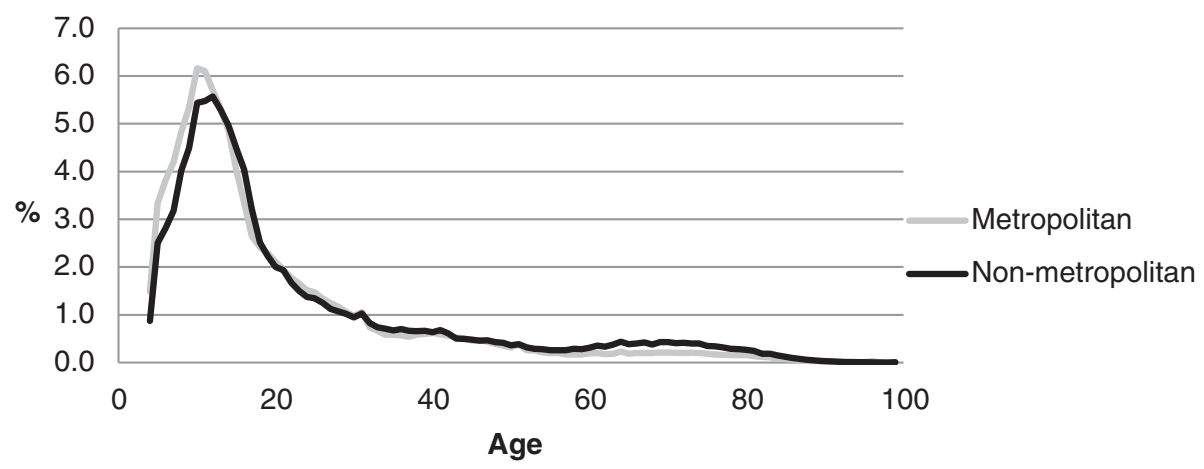

Fig. 3 Age profiles by geographical region

that this does not include all participants in these sports, such as those participating in school based programs or 'involved' participants for example those engaged in a non-physical manner such as coaches and officials [11].

Participation in club sport is clearly an activity dominated by young people. The peak representation for both males and females was 10-11 years. However, the 9-year age range across childhood for which the representation for each year of age was greater than $4 \%$ was younger for males (6-14 years) than for females (8-16 years). Furthermore, there were considerably more males participating aged $4-5$ years $(6 \%)$ than females at these ages $(2 \%)$.

Very few studies have provided age profiles of all registered participants in a sport; rather, the proportion of a study sample in sport at a given time has been reported $[16,25]$. Nevertheless, other studies in Australia have reported that sports participation peaked at $12-13$ years for boys and girls and fell by $50 \%$ by age 16 [12]. In a national Australian population survey, it was reported that in the 12 months prior to the survey $60 \%$ of all children aged 5 to 14-years participated in at least one organised sport activity outside of school hours [19]. The participation rates were $56 \%$ for 5-8 year olds, $66 \%$ for $9-11$ and $60 \%$ for $12-14$ year olds [19]. While the present study focuses on the age profile rather than participation rates, our results are consistent with the 2012 study; both report a lower peak participation age than the 2009 study. This may be the result of a growing trend to get children engaged in organised sport at a younger age via the increasing availability of modified sports programs. However the apparent increase in younger participants in sport and especially rising numbers in 4-5 year olds raises another issue. Younger children tend to sample sports, that is they typically play several different sports, and only when older, around 13 years, do they tend to specialise and focus their attention on one sport [26]. This is also the age when they are most likely either become involved in organised competitive sport or drop out of sport altogether [27]. However, the apparent tendency towards earlier participation in modified programs, and the consequent longer period between commencement and preparedness for specialisation and competition, may lead to a greater risk

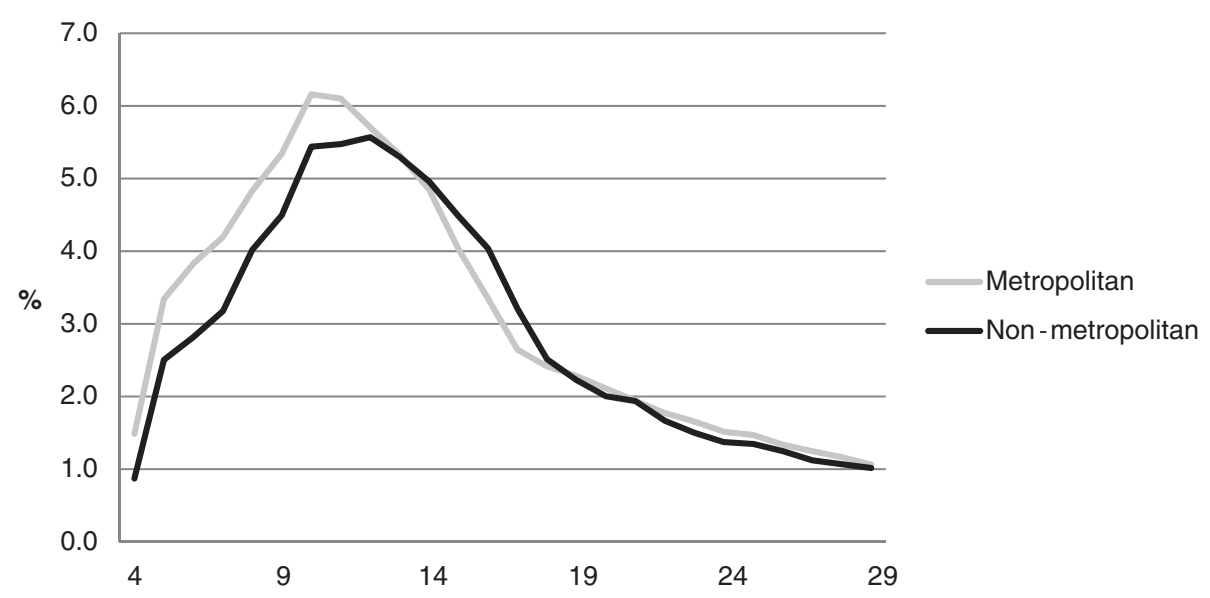

Fig. 4 Age profiles (4-29 years) by geographical region 
of dropout, either through boredom with an extended period in modified programs, or because of the temptation and/or pressure to transition prematurely into standard competitive forms of sport before their capacities are adequately developed [21]. Is there a risk that the specific targeting of very young children could have a negative effect on long term sport participation and potentially on social, mental and physical health outcomes? Further research is required to investigate whether the participation of very young children leads to higher or lower uptake of (organised) competitive sport later in childhood, and any affect that this may have on their health.

The reason that a greater proportion of males participate at a younger age than females is not known, however it may relate to boys being encouraged more to participate in sport at a young age than girls. There is some evidence to suggest that in families with male and female children, fathers tend to be more involved with their sons' sport than their daughters' [28]. Furthermore, parents influence children's sport participation [29] and this is shaped by the parents' own sporting backgrounds [28]. Since adult males are more likely to participate in sport than females [2], this may be a factor in encouraging the participation of young boys more than young girls.

While the development of modified sports programs for young children provide sporting opportunities to a new, wider, consumer segment, there are fewer opportunities for adolescents or adults to participate in sport outside standard club competition. Generally, sporting opportunities for children in the 10-14 age group in Australia and other nations such as the UK and Germany are focused on standard club competitions. Our study showed that the participation peaked for both males and females at age 11, and nearly a third of participants were aged between 10-14 years. This raises the question as to whether the available sport programs/opportunities are meeting the needs of adolescents and adults. Research has shown that whilst for those aged 15 years and older participation in leisure-time physical activity significantly increased over a 10 year period, participation in organised and/or club sport remained relatively stable [2]. It is evident that there are many individuals who wish to be active in their leisure-time, and health is often a major driver, but their interest in being physically active shifts away from traditional (organised, competitive) sport $[2,30]$. Participation in organised leisure-time activities (such as sport) is not as popular as non-organised activities among those aged 15 years and over, with roughly $27 \%$ participating in organised activities compared to $53 \%$ participating in non-organised activities at least once within a 12-month period [19]. It seems that the drop-off in sport participation during adolescence towards non-organised activities occurs at the same time when people would enter the elite sport pathway. Indeed, it has been suggested that as young people progress through early- to mid-adolescence, there are fewer and fewer opportunities to play sport for all but the most able and mature [31].

From an elite sport policy perspective, fewer individuals participating after the age of around 12 years would make the pool available for talent identification and elite pathway progression smaller. Researchers suggest that "talent identification models are likely to exclude many, especially late maturing, 'promising' children from development programmes due to the dynamic and multidimensional nature of sport talent" [32]. From a health policy perspective, fewer people active through sport may contribute to a range of negative health outcomes [33].

Fewer than ten per cent of the registered sport participants were adults aged 50 years and over. Exercise, fitness and team sports make up a greater proportion of the moderate and vigorous physical activity of young adults (16-24 years) compared to older adults (65+) [34]. A recent study found that, across both genders, there was no significant difference in the proportion of club sport participants across the ages from 15 to $75+$ [2]. However for younger females aged 15-34 participation was significantly higher than all other age groups (35-54, 55-74, and 75+ age groups), which did not differ significantly from each other [2]. As an ageing society, we should consider strategies to increase participation in sport for adults and older adults. In doing so, modifications may be required in sport products and equipment. There are many health benefits of sport participation for older adults, and many participate for social reasons, and enjoy playing with family members across generations [35].

In addition to age-related differences there were some notable geographic differences. A higher proportion of metropolitan children aged 4-13 participated in sport compared to non-metropolitan. The peak metropolitan participation age was younger, at age 10-11 years, compared to non-metropolitan, which peaked at 11-12 years. This may be related to the earlier provision (and a broader range of choice) of modified sports programs in metropolitan regions. However, adults and older adults represented a higher proportion of non-metropolitan than metropolitan participants. This may relate to the central role of community sport in Australian regional communities, where sport can be considered the 'social cement' [36], contributing to local identity [37], being 'held up as gauges of the health of country communities' [38], and crucial for increasing social connections and community cohesion [39]. It has been reported that in rural and regional areas, participation in sport for adolescent girls is a socially and culturally privileged activity, whereby involvement or lack of participation in club 
sport positions girls on one side of the physically active/ inactive binary categorisation [40]. This is sometimes related to perceived level of competency and lack of choices of activities in rural and regional areas.

Sports governing organisations generally have a strategic goal of increasing the level of participation within their sport. However, operationally their focus is often on development of the player/athlete segment of the population rather than recreational participants. Similarly, sport policy and funding in Australia, and other countries such as the UK and Canada, have been entrenched and focused on the elite level, often prioritising high performance over mass participation [41]. For example, an international analysis of government sport policies revealed that despite the existence of 'sport for all' policies emerging in a number of countries, these policies do not enjoy significant infrastructure or human resources support from governments to operationalise the policies, and in particular, do not enjoy the existence and stability of national institutes for elite sport [41]. The development of recreational pathways for sport participants therefore, requires a system-wide approach with cross-sectoral engagement of government and the sport and recreation industry if policy and organisational goals such as increasing sport participation are to be achieved. Ireland is one country that has proposed a hybrid model for participant/player development which not only maps out player/athlete development but also maps recreational pathways to ensure lifelong involvement in sport and physical activity [42]. Finland and the Netherlands also have a political and funding bias towards mass participation, and as a consequence have reported high participation rates compared to Australia, England, Canada and a number of European countries [41]. However, the definition and measurement of what constitutes sport participation varies between nations, which makes it difficult to make comparisons [41].

Redirecting sport policy and funding towards mass participation and the development of recreational pathways is one strategy to increase population levels of sport participation, and promote the health of individuals and communities. In this approach sporting organisations would need to be supported by government to monitor sport participation levels and the impact of sports programs. In another approach, the interests and needs of various population groups require consideration by governments and sporting organisations. However, it is much easier to argue changes to pathways and policies based on theory than it is to determine what are the critical process levers, community interests and stakeholders that will drive those changes. Researchers have suggested that socio-ecological models taken from physical activity research, and sport development concepts taken from sport management theory, be integrated to enhance efforts to increase sport participation $[8,9]$. This is particularly important as the determinants of sport participation are often examined within the broader context of leisure-time physical activity [43]. Most studies have examined sport participation focusing on adolescents [44-46]. For instance, a Canadian study of adolescent sport participation identified the need to fit sport into the "time-challenged, gender-stereotyped, highly technologized, cyber-filled lives of today's youth" [44]. Others have found that different sports have diverse participation determinants, particularly in regard to demographic and economic variables [47]. For instance, in a German study, swimming participation was positively influenced by being young or old (U-form relationship), female, well-educated and a native of the country; whilst football (soccer) participation was positively influenced by being young, male, less-educated and having a foreign nationality [47]. Individual and unorganised physical activities such as running, fitness/gymnasium and going for a walk or hiking were associated with middle age [47]. In Australia, market segmentation studies were recently conducted to better understand the Australian community's participation in sport and physical activities for both adults (aged 14-65) and children (aged 5-13 years) [48]. Consumer segments amongst the population were characterised to identify challenges and opportunities to engage and/or re-engage individuals in sport. For example, among children segments considered as potential sport participants included 'thrifty enthusiasts' who are positive about physical activity, but may not participate in activities organised in a community club; and 'ponderers' who would like to do more sport but are unsure how to get involved [48]. The underlying motivation for many sports participants, and especially young people is to have fun and socialise [39, 49]. Key factors that affect participation in sport include: 1) sport delivery that focuses on competition rather than fun and enjoyment; 2) a lack of flexibility around traditional sport club scheduling; 3 ) teams organised on the basis of talent rather than friendship groups; 4) limited opportunities for those with less sports competency; and 5) self-consciousness amongst adolescents, embarrassed by their lack of sporting ability [48].

This research on the determinants of sport participation and market segmentation raises some important questions regarding the delivery of sport and recreation. For instance, we contemplate whether organised sport can be modified in ways to cater for the needs of adolescent and adults, such as smaller fields, reduced time commitment, or flexibility in player rotations. In doing so, appropriate marketing would be required, as this has been a strength of modified sports programs for children [11]. The voluntary nature of the delivery of sport also needs to be considered in planning and implementing such programs. Others have suggested that alliances 
with more powerful organisations, particularly in the area of health, are required before sufficient resources can be allocated to promote mass participation [41] and that further collaboration between public health and sport management is required $[2,8]$.

\section{Conclusion}

In conclusion, this study is the first to examine the age profile of all registered participants in a major subnational geographical region within seven popular organised sports, across the lifespan. The majority of organised sport participation within these sports was by children aged 10-14 years, peaking at ages 10-11. The proportion of individuals engaged in these sports declined rapidly during adolescence, which may have health implications. Furthermore males and metropolitan participants were more likely to be represented in younger age categories compared to non-metropolitan participants.

Governments and sporting organisations alike have strategic and policy objectives to increase sport participation/mass participation; although these objectives are not sufficiently supported through the provision of infrastructure or resources that measure and analyse participation. A twin track approach to mass participation and elite performance may be required to achieve increases in sport participation as suggested by others [50], such as exemplified in Ireland [42]. In order to implement a twin track approach, further research is required to investigate reasons for attrition more closely especially relating to the very young participant cohorts, to inform program design and to test the efficacy of such programs for promoting an active and healthy nation.

\section{Abbreviations}

ABS: Australian Bureau of Statistics; LGA: local government areas; LTPA: leisure time physical activity; PA: physical activity; SSA: state sporting associations.

\section{Competing interests}

The authors declare that they have no competing interests.

\begin{abstract}
Authors' contributions
RME, MMC contributed to the study design, interpretation of results, manuscript conceptualisation and preparation. JTH and MJC contributed to the study design, data management, statistical analysis and interpretation, manuscript conceptualisation and preparation. HW and WRP contributed to the interpretation of results and manuscript preparation. All authors have read and approved the final manuscript.
\end{abstract}

\section{Acknowledgements \\ We thank the Victorian State Sporting Associations (Australian Football League, Tennis, Netball, Basketball, Cricket, Hockey and Lawn Bowls) for providing the data on which this research was based. Rochelle Eime was supported by a VicHealth Research Practice Fellowship- Physical Activity}

Received: 24 July 2015 Accepted: 1 March 2016

Published online: 12 March 2016

\section{References}

1. Kumar A, Rossiter P, Olczyk A. Children's participation in organised sporting activity. In: Research Paper Cat No 1351055028. Canberra: Australian Bureau of Statistics; 2009

2. Eime R, Sawyer N, Harvey J, Casey M, Westerbeek H, Payne W. Integrating public health and sport management: sport participation trends 2001-2010. Sport Manage Rev. 2015;18(2):207-17.

3. Eime R, Young J, Harvey J, Charity M, Payne W. A systematic review of the psychological and social benefits of participation in sport for children and adolescents: informing development of a conceptual model of health through sport. Int J Behav Nutr Phys Act. 2013;10:98.

4. Eime R, Young J, Harvey J, Charity M, Payne W. A systematic review of the psychological and social benefits of participation in sport for adults: informing development of a conceptual model of health through sport. Int J Behav Nutr Phys Act. 2013;10:135.

5. Eime R, Harvey J, Payne W. Dose-response of women's Health-Related Quality of Life (HRQoL) and life satisfaction to physical activity. J Phys Act Health. 2014;11:330-8.

6. Dohle S, Wansink B. Fit in 50 years: participation in high school sports best predicts one's physical activity after Age 70. BMC Public Health. 2013:13(1):1100.

7. Scheerder J, Thomis M, Vanreusel B, Lefevre J, Renson R, Enynde B, et al. Sports participation among females from adolescence to adulthood: a longitudinal study. Int Rev Sociol Sport. 2006;41(3):413-30.

8. Rowe K, Shilbury D, Ferkins L, Hinckson E. Sport development and physical activity promotion: an integrated model to enhance collaboration and understanding. Sport Manag Rev. 2013;16(3):364-77.

9. Henderson KA. A paradox of sport management and physical activity interventions. Sport Manag Rev. 2009;12(2):57-65.

10. Commonwealth of Australia. National sport and active recreation policy framework. In. Canberra: Commonwealth of Australia; 2011

11. Eime R, Payne W, Harvey J. Trends in organised sport membership: Impact on sustainability. J Sci Med Sport. 2009;12(1):123-9.

12. Olds T, Dollman J, Maher C. Adolescent sport in Australia: Who, when, where and what? ACHPER Healthy Lifestyles Journal. 2009;56(1):11-6.

13. Maia JAR, Lefevre J, Claessens AL, Thomis MA, Peeters MW, Beunen GP. A growth curve to model changes in sport participation in adolescent boys. Scand J Med Sci Sports. 2010;20(4):679-85.

14. Eime R, Harvey J, Sawyer N, Craike M, Symons C, Polman R, et al. Understanding the contexts of adolescent female participation in sport and physical activity. Res Q Exerc Sport. 2013;84(2):157-66.

15. Van Tuyckom C, Scheerder J, Bracke P. Gender and age inequalities in regular sports participation: a cross-national study of 25 European countries. J Sports Sci. 2010;28(10):1077-84.

16. Palacios-Ceña D, Fernandez-de-Las-Peñas C, Hernández-Barrera $V_{\text {, Jiménez- }}$ Garcia R, Alonso-Blanco C, Carrasco-Garrido P. Sports participation increased in Spain: a population-based time trend study of 21381 adults in the years 2000, 2005 and 2010. Br J Sports Med. 2012;46(16):1137-9.

17. Cozijnsen R, Stevens N, Van Tilburg TG. The trend in sport participation among Dutch retirees, 1983-2007. Ageing Soc. 2013;33(04):698-719.

18. Scheerder J, Vanreusel B, Taks M. Stratification patterns of active sport involvement among adults: social change and persistence. Int Rev Sociol Sport. 2005;40(2):139-62.

19. Sports and physical recreation: A statistical overview, Australia 2012 [http://www.abs.gov.au/ausstats/abs@.nsf/Latestproducts/4156. OMain\%20Features12012?opendocument\&tabname=Summary \& prodno $=4156.0 \&$ issue $=2012 \&$ num $=\&$ view $=$ ].

20. Standing Committee on Recreation and Sport: Participation in exercise, recreation and sport. In. Canberra: Australian Sports Commission; 2010.

21. Eime R, Casey M, Harvey J, Charity M, Young J, Payne W. Participation in modified sports programs: a longitudinal study of children's transition to club sport competition. BMC Public Health. 2015;15:649.

22. Australian Bureau of Statistics. Australian Statistical Geography Standard (ASGS): Volume 3- Non ABS Structures, Cat.No.1270.0.55.003. In. vol. Catalogue number 1270.0.55.003. Canberra: Australian Bureau of Statistics; 2011.

23. Australian Bureau of Statistics. ABS Postal Area Concordances, Cat.No.1270.0. 55.006. In., vol. Catalogue number 1270.0.55.006. Canberra: Australian Bureau of Statistics; 2011.

24. Local Government Areas in Metropolitan Melbourne [http://www. liveinvictoria.vic.gov.au/living-in-victoria/melbourne-and-regional-victoria/ melbourne\#.VNBGp00cTiw]. 
25. Stamatakis E, Chaudhury M. Temporal trends in adults' sports participation patterns in England between 1997 and 2006: the Health Survey for England. Br J Sports Med. 2008;42(11):901-8.

26. Cote J, Vierimaa M. The developmental model of sport particiation: 15 years after its first conceptualization. Rev Sci Sports. 2014;29:S63-9.

27. Côté J, Hay J. Children's involvement in sport: A developmental perspective. In: Silva JM, Stevens DE, editors. Psychological foundations of sport. 2nd ed. Boston, MA: Allyn \& Bacon; 2002. p. 503-19.

28. Wheeler $\mathrm{S}$. The significance of family culture for sports participation. Int Rev Sociol Sport. 2012;47(2):235-52.

29. Eime R, Harvey J, Craike M, Symons C, Payne W. Family support and ease of access link socio-economic status and sports club membership in adolescent girls: a mediation study. Int J Behav Nutr Phys Act. 2013;10:50.

30. Hajkowicz S, Cook H, Wilhelmseder L, Boughen N. The future of Australian sport: Megatrends shaping the sports sector over coming decades. In CSIRO; 2013

31. Kirk D. Physical education, youth sport and lifelong participation: the importance of early learning experiences. Eur Phys Educ Rev. 2005;11(3):239-55.

32. Vaeyens R, Lenoir M, Williams AM, Philippaerts RM. Talent identification and development programmes in sport: current models and future directions. Sports Med. 2008:38(9):703.

33. Eime R, Harvey J, Charity M, Casey M. Physical activity, sport and health in the City of Brimbank: A report to Mitchell Institute for Health and Education Policy. In.: Federation University, Victoria University; 2014.

34. Bélanger M, Townsend N, Foster C. Age-related differences in physical activity profiles of English adults. Prev Med. 2011;52(3-4):247-9.

35. van Uffelen J, Jenkin CW, HW, Biddle S, Eime R. Active and healthy ageing through sport. Report prepared for the Australian Sports Commission. Melbourne: Victoria University; 2015.

36. Mugford S. The status of sport in rural and regional Australia: Literature, research and policy options. In:: Qualitative and Quantitative Social Research, Adelaide, Australia; 2001.

37. Tonts M. Competitive sport and social capital in rural Australia. J Rural Stud. 2005;21:137-49.

38. Gard M. Sport, physical education and country towns: diverse enough? Educ Rural Aust. 2001:11:19-26.

39. Eime R, Payne W, Casey M, Harvey J. Transition in participation in sport and unstructured physical activity for rural living adolescent girls. Health Educ Res. 2010;25(2):282-93.

40. Mooney A, Casey M, Smyth J. "You're no-one if you're not a netball girl": rural and regional living adolescent girls' negotiation of physically active identities. Ann Leis Res. 2012;15:19-37.

41. Nicholson M, Hoye R, Houlihan B. Participation in Sport: International Policy Perspective. London: Routledge; 2010.

42. Macphail A, Kirk D. Young people's socialisation into sport: experiencing the specialising phase. Leis Stud. 2006;25(1):57-74.

43. Craggs C, Corder K, van Sluijs EMF, Griffin SJ. Determinants of change in physical activity in children and adolescents: a systematic review. Am J Prev Med. 2011:40(6):645-58.

44. Berger IE, O'Reilly N, Parent MM, Séguin B, Hernandez T. Determinants of sport participation among Canadian adolescents. Sport Manag Rev. 2008;11(3):277-307.

45. Cox L, Coleman L, Roker D. Determinants of sports and physical activity participation amongst 15-19 year-old young women in England - Final report on research commissioned by Sport England. In.: Trust for the Study of Adolescence (TSA); 2005.

46. Taggart A, Sharp S. Adolescents and sport: determinants of current and future participation In. Perth: Sport and Physical Activity Research Centre, Edith Cowan University; 1997.

47. Breuer C, Hallmann K, Wicker P. Determinants of sport participation in different sports. Manag Leis. 2011;16(4):269-86.

48. Australian Sports Commission. Market segmentation for sport participationadults. In., vol. March. Canberra: Australian Sports Commission; 2013.

49. Casey M, Eime R, Payne W, Harvey J. Using a socioecological approach to examine participation in sport and physical activity among rural adolescent girls. Qual Health Res. 2009;19(7):881-93.

50. Collins D, Bailey R, Ford PA, MacNamara Á, Toms M, Pearce G. Three worlds: new directions in participant development in sport and physical activity. Sport Educ Soc. 2011;17(2):225-43.

\section{Submit your next manuscript to BioMed Central and we will help you at every step:}

- We accept pre-submission inquiries

- Our selector tool helps you to find the most relevant journal

- We provide round the clock customer support

- Convenient online submission

- Thorough peer review

- Inclusion in PubMed and all major indexing services

- Maximum visibility for your research

Submit your manuscript at www.biomedcentral.com/submit
Biomed Central 